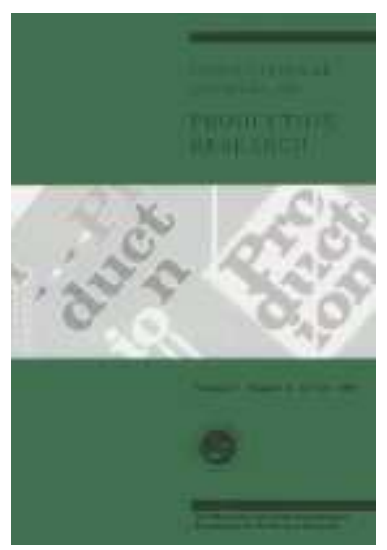

\title{
18th ICPR paper: A NEW VALUE STREAM MAPPING APPROACH FOR COMPLEX PRODUCTION SYSTEMS
}

\begin{tabular}{|r|l|}
\hline Journal: & International Journal of Production Research \\
\hline Manuscript ID: & TPRS-2005-IJPR-0503 \\
\hline Manuscript Type: & Original Manuscript \\
\hline Author: & 01-Dec-2005 \\
\hline & $\begin{array}{l}\text { Complete List of Authors: } \\
\text { Productia, Marcello; Università di Pisa, Mechanineal Nuclear and } \\
\text { Production Engineering } \\
\text { Zammori, Francesco; Università di Pisa, Mechanical Nuclear and } \\
\text { Production Engineering }\end{array}$ \\
\hline Keywords: & LEAN MANUFACTURING, ROUTING \\
\hline Keywords (user): & Value Stream Mapping, Temporized Bill of Material \\
\hline &
\end{tabular}

\section{ScholarONE" \\ Manuscript Central}




\title{
A NEW VALUE STREAM MAPPING APPROACH FOR COMPLEX PRODUCTION SYSTEMS
}

\author{
Marcello BRAGLIA* , Gionata CARMIGNANI, Francesco \\ ZAMMORI \\ Dipartimento di Ingegneria Meccanica, Nucleare e della Produzione, \\ Università di Pisa, \\ Via Bonanno Pisano, 25/B - 56126 PISA (Italy)
}

\footnotetext{
${ }^{*}$ Corresponding author:

Marcello BRAGLIA
}

Dipartimento di Ingegneria Meccanica, Nucleare e della Produzione Via Bonanno, 25/B 56126 PISA (Italy) phone: +39050913029 Fax: +39050913040 e-mail: m.braglia@ing.unipi.it 


\title{
A NEW VALUE STREAM MAPPING APPROACH FOR COMPLEX PRODUCTION SYSTEMS
}

\begin{abstract}
In this paper an innovative framework to apply Value Stream Mapping to products with complex Bill of Materials is presented. Value Stream Mapping is one of the best tools to map a process and to identify its main criticalities. Unfortunately it can be effectively applied only to linear systems. When the manufacturing process is complex with flows merging together, Value Stream Mapping cannot be straightly used. Thus, the main objective of this work consists in the solution of this limitation so that lean production can be enhanced in complex systems too. The proposed approach is based on seven iterative steps and integrates Value Stream Mapping with other tools typical of industrial engineering. The basic idea is to execute a preliminary analysis to identify the "critical production path" using the Temporized Bill of Material. Then, improvements are made considering all possible sharing with others secondary paths, as possible constraints. Once the critical path has been optimized, a new one may become critical. Thus the analysis proceeds iteratively until the optimum is reached and the Work In Process level has decreased under a desired value. A case study taken from a real setting environment is finally presented to asses the validity of the methodology here proposed.
\end{abstract}

Keywords: Lean Manufacturing, Routing, Temporized Bill of Material, Value Stream Mapping

Words Number: 6240 


\section{INTRODUCTION}

Lean Production, a concept based on Toyota Production System, has emerged recently as a global approach that integrate different tools to focus on waste elimination and to manufacture products that meet customer's needs and expectations in a better way (Hines and Taylor, 2000). The main concept of Lean Production consists in the specification of what create value for the end customer and in the accomplishment of this specifications by aim of a production system striving for perfection and characterized by a strained and leveled flow, pulled by customer's demand.

In particular, once "value" has been defined, Lean Production development requires the analysis of the "value stream", being all activities - both value-added and non-value added - that are currently needed to bring a specific product from raw material to the end customers. Next, wasteful steps have to be eliminated and flow can be introduced in the remaining "value-added" processes (Womak and Jones, 1996).

In technical literature, various authors have defined a suite of tools and techniques to implement Lean Production in a structured way. Emiliani (2000) used the primary Lean Production support tools to develop a practical solution-oriented method to achieve business goals. The final result consists in a framework that unifies technical and behavioral components of management.

Hines and Rich (1997) proposed a set of seven tools derived from industrial engineering to support the waste removal process.

In this paper we focus on Value Stream Mapping (VSM) a tool more focused on the entire value stream of a productive process. VSM is a mapping tool that is used to map a productive process or an entire supply chain networks. It maps not only material flows but also the information flows that signal and control production. 
Tapping et al. (2002) introduced a step by step procedure to perform a VSM analysis. The first step consists in the selection of a product family as the target for the improvement and in the construction of the "Current State Map" (CSM) for the selected product value stream. The CSM must be based on a set of data collected directly on the shop floor and should be drawn using the set of standard icons shown in Figure 1.

Figure 1 Here

The next step consists in the identification and analysis of the wastes encountered along the value stream. Finally a "Future State Map" (FSM) is design to represent the ideal production process without the removed wastes.

Also the FSM should be drawn using a set of standard icons shown in Figure 2 and it can be obtained answering eight questions reported in Table 1 (Lian and Van Landeghem, 2002).

Figure 2 Here

Table 1 Here

In respect to other mapping techniques, VSM offers several advantages:

- it forms the basis for Lean Production implementation;

- it relates the manufacturing process internal to the facility to the whole Supply Chain;

- it displays both the product flow and the information flow;

- it links "Products Planning" and "Demand Forecast" to "Production Scheduling" and to "Flow Shop Control"; 
- it includes information related to production time as well as information related to inventory levels.

Unfortunately VSM has also two main drawbacks:

- basically it is a paper and pencil based technique, thus the accuracy level is limited and the number of versions that can be handled is low;

- in real settings, many companies are of a "high variety-low volume type", meaning that many value streams are composed of hundreds of industrial parts and products. Thus this complication cannot be addressed with the standard method.

In particular VSM can be effectively used only for productive systems characterized by linear product routings. If the production process is complex VSM application breaks down as it fails to map value streams characterized by multiple flows that merge. This typically happens for products described by a complex Bill of Material (BOM), manufactured in a job shop facility. In such cases Rother and Shook (1999) suggested to map only the key elements of the flow and to "draw one flow over another" if necessary. Still no decisional process is proposed to choose the key elements of the value stream. Furthermore, identifying which flows are identical or even similar is not a trivial activity for any but the easiest of the real production process.

In technical literature these problems have been firstly addressed in three different works.

McDonald et al (2002) applied VSM to a "three parallel lines assembly process" using discrete event simulation to define the basic parameters for the FSM. They demonstrated that, in case of production complexity, simulation can provide important information for the FSM implementation.

Lyan and Van Landeghem (2002), followed a similar approach to map a "two parallel line" push system. Two simulation models were built for the push and pull systems 
respectively and the key measurements such as lead times, throughput rates, valueadded ratios were compared as well as evaluated.

Khaswala and Irani (2004) improved a welding job shop facility by aim of a new mapping approach called "Value Network Mapping". This technique was derived from an integration of PFAST (Production Flow Analysis and Simplification Toolkit) and VSM (Irani and Zhou, 2003). It was proved that this approach supports facility improvements, such as the creation of manufacturing cells and improvements in the current material handling methods.

In this work, an alternative and innovative framework for a structured application of VSM to products requiring non-linear value streams, is proposed. The framework is based on a recursive procedure and integrates the classic VSM technique with different tools derived from the manufacturing engineering area. The underlying idea among the method is to execute a preliminary analysis to identify the longer critical production path by aim of the Temporized Bill of Material (TBOM). Clearly the improvement process will start from the critical path that is responsible for the whole Lead Time of the productive process. Once the critical path has been identified, possible improvements are searched, considering all sharing with secondary paths as further constraints. Finally, when the main value stream has been improved, a new path may become the critical one. Thus the analysis proceeds iteratively until the optimum is reached or the Work in Process (WIP) level has decreased under the desired level. In that way the framework makes it possible to explore the overall production process determining the correct order of the path to be improved. 


\section{IMPROVED VALUE STREAM MAPPING PROCEDURE (IVSM)}

The framework follows an iterative procedure based on the set of seven steps listed below:

1. select a product family;

2. identify machine sharing;

3. identify the main value stream;

4. map the critical path;

5. identify and analyze wastes;

6. map the future state for the critical/sub-critical path;

7. identify the new critical path and iterate the process;

The procedure is shown as a flow diagram in Figure 3.

Figure 3 Here

\subsection{Step 1: "Select a Product Family"}

The first step of the framework consists in the identification of the product families and in the selection of one as the initial target for the improvement.

Performing a Product Quantity Analysis (PQ Analysis) is a classical approach for product mix segmentation. This method is used to display the product mix in the form of a Pareto chart, sorting the products in order of decreasing production quantity. In that way it is possible to understand how the total quantity is distributed among different product types. The underlying logic of PQ analysis is that high volume products are responsible for the largest part of non-value added costs such as: material handling, WIP, queuing and other operational costs. Therefore, focusing on high volume value stream should boost the overall performances of the factory. When a more 
representative product set is needed, it is possible to include the sell revenue as an additional parameter for the ABC analysis. To do that, two distinct Pareto Analysis" (PQ\$ analysis) must be performed. The first one should sort the products in order of decreasing production quantity, while the second one should sort the products in order of decreasing selling revenue. Therefore, the combination of the two Pareto analysis leads to the definition of nine distinct products classes ranging from AA (upper grade) to $\mathrm{CC}$ (lower grade). Such interrelation can then be expressed using a classification matrix, which show how products are distributed among each of the nine classes previously defined. An example of a PQ\$ Pareto Analysis is shown in Figure 4.

Figure 4 Here

\begin{abstract}
Although PQ $\$$ analysis is the easiest way for product mix segmentation, when the Pareto chart displays a 40:60 or even less PQ ratio (as typically happens in job shop facility), a different approach is needed to choose the target value stream.

Since a product family is defined as "a group of products that pass through similar processing steps and over common equipment in the downstream processes", it is possible to group product into families through the analysis of the Multi Product Process Chart (MPPC) or, alternatively, of the Machine-Part Matrix (MPM). An example of a Multi product Matrix is shown in Table 2.
\end{abstract}

Table 2 Here 


$$
S_{i j}=\frac{X_{i j}+\sqrt{X_{i j} \cdot Y_{i j}}}{X_{i j}+X_{i}+X_{j}+\sqrt{X_{i j} \cdot Y_{i j}}}
$$

where:

- $0<=\operatorname{Sij}<=1$;

- $\mathrm{Xij}=$ Number of machines used by both part " $\mathrm{i}$ ” and part “ $\mathrm{j}$ ” (number of matches);

- $\mathrm{Xi}=$ Number of machines used by part " $\mathrm{i}$ ” only;

- $\quad \mathrm{Xj}=$ Number of machines used by part “j”" only;

- $Y \mathrm{ij}=$ Number of machines that are used neither by part " $\mathrm{i}$ ” nor by part “ $\mathrm{j}$ " (number of misses);

For further explanation on the most used similarity function please see also Veramani and Mani (1996) and Offodile and Grznar (1997).

An example of cluster analysis application concerning the formation of part families is briefly reported in Table 3 and Figure 5. In particular, Table 3 shows the PWSC obtained applying the Jaccard similarity function to the MPM presented in Table 2, while shows the resulting dendrogram of the part families, obtained using the "single linkage clustering algorithm (SLCA). Figure 5 shows the resulting dendrogram for the obtained part families. 
Table 3 Here

Figure 5 Here

Finally, once items have been grouped into clusters, the target value stream can be identified simply applying a PQ\$ analysis to the part families themselves, as previously explained.

\subsection{Step 2: "Identify machine sharing"}

The second step of the framework consists in the identification of the machines that, being shared by more than a product family, act as a possible constraint for lean production implementation. In particular, to achieve a continuous and leveled flow, a facility layout must possess the following characteristics:

1) flow between consecutive pairs of operations takes place over short travel distances;

2) flow is unidirectional with minimum backtracking or cross flows between machines;

3) flow paths in the cell must consist of smooth contours.

Machines that are dedicated to a single product family represent an opportunity to improve the layout structure through the implementation of autonomous "Cellular Manufacturing System" (CMS). On the contrary, machines that are shared by products belonging to different families, act as constrains to the fulfillment of the layout requirements. This is called "external sharing" due to the fact that, unless machine duplication, it will be impossible to develop a set of completely unrelated manufacturing cell. Thus some products will be forced to move from one cell to another one, to complete its own processing sequence. Furthermore, external sharing represents 
an additional constrain to flow synchronization between cells. Thus, before proceeding with VSM, it is necessary to identify all the machines that are used by more than a family.

External sharing can be easily derived from the analysis of the MPM, after the order of both its columns and its rows have been rearranged in the following way:

- the columns (part labels) should be interchanged in order to reproduce the part families previously identified;

- the rows (machine labels) should be interchanged in order to gather along the main diagonal the maximum amount of positive elements (elements equals to 1).

In this way the machine tends to cluster into autonomous CMS, each one corresponding to a single part family. On the contrary the positive elements distributed far from the diagonal represent the parts that need to be moved from one cell to another, or machines that need to be replicate in another cell. The MPM can be reallocated through an automatic procedure essentially in two different way: "array based method" or "hierarchical clustering method".

The array-based methods can be stated as follows: "given a Boolean incidence matrix (MPM), partition it into a maximal number $(C)$ of clusters, $C>2$, such that the number of exceptional elements is minimized" (Selim et al, 2003). Many array based methods are reported in literature (Veramani and Mani, 1996; Offodile and Grznar 1997; Selim et al, 2003). All array based methods proceed by rearranging the rows with the leftmost positive cells to the top and the columns with the top-most positive cells to the left of the MPM, so that, after several iterations, all the positive cells will form diagonal blocks from the top left corner to the bottom-right corner of the matrix. On the other hand, hierarchical clustering methods make a partition into clusters for both machines and 
parts and then rearrange the rows and the columns of the MPM, accordingly with the defined families, to obtain the same "diagonal block form" of the matrix.

In Table 4 is shown a possible solution to the stated problem for the MPM matrix reported in Table 2.

Table 4 Here

As displayed by the matrix, there are six (out of fifteen) machines affected by "external sharing”. Considering Family Three (F\#3) as an example, one can notice that M\#15 and M\#12 are used also by products belonging to $\mathrm{F} \# 1$ and $\mathrm{F} \# 2$ respectively. For this reason it would not be possible to analyze F\#3 value stream as if it was independent from the other families. In particular, due to machine sharing, two additional constrain will have to be added.

In agreement with the "Lean principle" that states to substitute single high volume equipment with a set of similar, yet smaller and more flexible machines, it seems plausible to replace M\#15 with two independent machines. In fact in this case both the new machine would experiment a high level of usage being used by two and three products respectively. The same cannot be said for M\#12 which is used by $\mathrm{P} \# 3$ only. In this case, if an additional machine was placed in the third cell it will experiment a low usage rate. A possible solution to synchronize the flow and to develop a pull system without an additional machine is displayed in Figure 6.

Figure 6 Here

Due to the fact that M\#12 is shared, it cannot be leveled on the mix micro and must produce in batch, multiple of the pitch. Still M\#12 needs to be linked to the other cell in 


\subsection{Step 3: "Identify the main value stream"}

As previously stated, when dealing with non-linear production processes characterized by multiple flows that merge, mapping and improving the whole process at the same time, is not easy and usually not even feasible. Thus the mapping process should begin from the main (critical) value stream. Afterwards, following an iterative process, the analysis should embrace the other branches of the process in a second moment and only if needed to improve the overall performances of the system.

One of the main objective of VSM is to reduce the time it takes a piece to move all the way through the process (i.e. Lead Time) and consequently to cut down the WIP as well as the finished good inventories. Thus the critical path can be defined as the processing sequence which is responsible for the total production time that determines the minimum time frame needed to schedule production in advance. In that sense, the underlying logic beyond the proposed approach states that if the critical path is targeted as the starting point for the analysis, then any improvements obtained through VSM is 
directly converted in an overall LT reduction. The BOM is the element that links the productive sequence with the LT needed to perform each manufacturing operation, so it is natural to derive the critical path from the analysis of the BOM itself. For that purpose in particular, the TBOM is preferable. This is because the TBOM is a graphical representation of the operations as well as the time taken to manufacture a product. In particular, in a TBOM the vertical segments linking each level of the productive process, are proportional in length to the LT requested to perform the corresponding operation. Therefore, as shown in the Figure 7, the critical path can be simply obtained selecting the production sequence characterized by the maximum vertical length.

Figure 7 Here

The TBOM shows both the supply and the production LT with a hatch and straight line respectively. Therefore, before choosing the critical path, it is necessary to asses if the VSM is intended to cover the global value stream, or if it is just intended to cover the manufacturing value stream inside the facility. In the second case, the first level of the TBOM referred to suppliers should not be considered in the critical path selection.

As exemplified in Figure 7, in order to simplify the mapping process, it is advisable to identify on the critical path the manufacturing operations that are performed with a shared resource. It is important to make a clear distinction between internal sharing (i.e. a machine that is used by different components of the same product) and external sharing (i.e. a machine that is used by different product families).

\subsection{Step 4: "Critical path mapping"}

The fourth step consist in the construction of the "Current-State-Map" for the critical value stream. 
Data collection should follow the approach recommended by Rother and Shook (1999). It should begin at shipping, working backwards in the production process to row materials or suppliers and collecting snapshot data on inventory level at each stage of the value stream. Since VSM has the unique feature to record the information flows associated with the material flows in the same map, the following data should be collected:

- Information Flow:

- type of orders released by customers (ordinary, planned, opens etc.);

- type of orders released to first tier suppliers (ordinary, planned, opens etc.);

- ordering frequency;

- forecast frequency;

- system used to plan production;

- time frame to plan production;

- Machines:

- set up time;

- up time;

- cycle time;

- $\mathrm{n}^{\circ}$ of operators;

- $\mathrm{n}^{\circ}$ of shifts/hours per day;

- cycle time;

- Production Flow:

- average customers demand;

- shipping frequency; 
- pallets dimension;

- production batches;

- inventory levels;

- type of flow between machine (push-pull).

When all the data have been collected, the CSM can be constructed using the VSM standard icons. Due to the fact that the obtained representation is limited to the critical path, there is the additional need to identify on the map all the machines that are shared, as well as the insertion points where secondary branches merge with the main value stream. Moreover, when a machine is shared, the percentage of time that is used by each family must be inserted as an additional data in the corresponding "Machine Data Box".

\subsection{Step 5: "Waste identification"}

The fifth step of the framework consist in the analysis of non value added activities that are displayed on the actual state map. To do that it can be helpful to use a suite of tools expressly designed to identify and to remove waste origin in individual value stream (Hines and Rich, 1997).

Once the wastes and the relative causes have been detected, it is necessary to evaluate if such problems are linked to inefficiency spread among the whole critical stream or if they are concentrated in correspondence of the insertion points.

This should be the case of an assembly station fed by two items "A" and "B" coming from the main and a secondary value stream respectively. If the average LT for that station is high due to frequent starving caused by lacking in product B replenishment, then the cause of the waste (which correspond in an abnormal increase of A stock level in front of the station) must be searched in the secondary branch of the process. To highlight such situation it could be useful to split the downtime recorded for each 


\subsection{Step 6.1: "Main Stream Future state mapping"}

The sixth step consists in the construction of the FSM for the critical value stream. The map should be defined using the VSM standard icons and trying to answer the "eight future state question".

To do that the following approach can be used:

a) Using the TBOM, divide the critical value stream into a set of adjacent segments. Each segment must be confined between two consecutive insertion point, with the exception of the first one. This one starts with the first operation of the process and end at the first insertion point.

b) Select the last segment as the future-state implementation starting point:

b.1.) If machines are not shared, join them into a cell (continuous flow processing) whenever possible. "One by one manufacturing is in fact the best way to level flow and to reduce inventory level. Alternatively use a Kanban pull system to link machines and to synchronize flow between them.

b.2.) If a machine is affected by internal sharing, as shown in Figure 8 (where both RM1 and B1 are components of the same product), two alternative solutions are possible:

Figure 8 Here 
b.2.1.) Due to the fact that the Takt Time is the same for both operation on M2 (internal sharing), if the Cycle Time of the three machines considered is equal or less a half Takt Time (CT1\&CT2\&CT3 $<=0.5^{*}$ Takt Time), then M1, M2, M3 can be joined into a manufacturing cell and a continuous flow process can be established. In this hypothetical situation two operators are needed. The first one is fixed on M2 while the second skips alternatively between M1 and M2. The main constrain to this solution is constituted by machines Cycle Time and by Set-Up time that must be practically reduced to zero.

b.2.2.) Alternatively it is possible to use a "FIFO Lane" served by three operators, to connect each machine. The only constrain to this solution is represented by M2 Cycle Time that , as previously, must be equal or less than a half Takt Time. Using this solution is also advisable to define "a priori" the production sequence on M2, in order to maintain the correct Takt Image.

b.3.) If a machine is affected by external sharing, generally the only available solution is represented by the use of a "Signal Kanban". In that way, the shared resource is allowed to produce in batches bigger then the optimum pitch, still pulled by the downstream resources.

c) Typically, in correspondence of an insertion point a continuous flow is not feasible. This is due to the fact that production information must be simultaneously communicated to two or even more value streams that merge at that point of the line. Thus, on the main value stream, the station at the insertion point can be included in a continuous flow only if a visual control based on a reorder point is sufficient to pull production of the other value stream and a leveled pace is not essential. In all other 
cases, an alternative solution is to establish flow using different lean techniques such as the single - double Kanban pull system.

d) Choose the next segment of the original value stream and apply iteratively the method starting from step "b" to step "d" until all the adjacent segments have been considered.

\subsection{Step 6.2: "Secondary Stream Future state mapping"}

When the main problems are caused by inefficiency located on a secondary branch of the process, this branch must be analyzed before performing any attempt to improve the main value stream. To do that, an CSM of the secondary value stream must be construct following the approach described in Step 4 and 5. When the CSM has been made, the cause of waste must be identified and a FSM derived to. eliminate the inefficiencies for the critical path. The FSM of the secondary branch must be developed following the approach described in Step 6.1.

Finally, when the secondary branch of the process has been optimized, the analysis skip back to the main value stream. If its external problems have been solved it can be finally improved following the approach described in "Step 6.1".

\subsection{Step 7: "Process Iteration"}

The seventh step of the framework consists in the application of the method to other branches of the productive process. To choose the next value stream to be taken as the targeted for the improvement, the TBOM need to be modified in relationship to the LT reduction obtained through the modifications introduced in the process. In that way it is possible to asses if the new total LT is still determined by the improved main value stream or if it is now determined by another value stream. 
In the first case, the procedure can be arrested. In fact, from a further application of the method, a reduction in inventory and handling cost should be obtainable, yet it would be impossible to reduce the total production time any more.

On the contrary, if the total production time is now determined by another branch, this becomes the new critical path and the procedure restart from Step 4. Proceeding in this way it is possible to analyze the various branches of the productive process, following a structured iterative procedure that comes to an end when the global process has been optimized or, alternatively, when the total production time can not be shortened any more.

\section{DESCRIPTION OF CASE APPLICATION}

To asses the validity of the method here proposed, a real productive process was analyzed and a possible lean solution developed. This application was implemented within an electro domestic manufacturing firm considering in particular the plant devoted to refrigerators production. The organization's identity is protected and productive information cannot be released, thus some data were purposely altered. In the next part of the paper, we will simply refer to the plant as Refrigerator Manufacture (RM).

To execute the IVSM approach, a design team was assembled with people having different skills and competences, with the aim to define the actual state map and the desired future state map for the 150 liters refrigerator line. This kind of domestic refrigerator was chosen for it accounts for $60 \%$ of the overall production. In particular, RM manufacturers three families of 150 liters refrigerators, type A, type B and type C in same quantities. The productive process is similar for all three types and, across each families, there are just little differences both in processing time and in set up times. 
As shown in Figure 9, each 150 liters refrigerator is manufactured as four parallel subassemblies (body, door, condenser pipe, electronic devices), each one converging in a different stages of the main assembly process.

Figure 9 Here

A weekly MRP schedule, based on demand forecast, is generated for each stream of the process to push orders through production. In addition, a supervisor is in charge to control production and to make daily adjustments to solve possible problems and to fulfill urgent orders.

\subsection{Actual State Mapping}

To built the CSM, the TBOM, was firstly analyzed to identify the critical value stream determining the total production LT. As clearly shown in Figure 10, the critical value stream begins with sheets cutting, proceeds with the refrigerator body assembly and ends at the final check and packaging. The estimated Lead Time is equal to seven days, that is the period used to schedule production in advance.

\section{Figure 10 Here}

Once the critical path was identified, the next step was to collect all data necessary to create the CSM of the process. This was done walking backwards from the "packaging" to the "sheets cutting", taking snapshot of the encountered WIP and inventories level. The obtained CSM for the critical value stream is shown in Figure 11.

Figure 11 Here 
Please note that only the operations belonging to the critical path are represented, while the secondary branches are drawn as "empty boxes", just to show their insertion points in the main value stream. Another difference with traditional CSM consists in the fact that some process boxes are represented with a dotted interior. This icon is used to identify the shared resources. In particular RM manufactures also commercial refrigerators with an interior capacity of 300 liters. These are manufactured on a dedicated assembly line, with the exception of the sheets cutting operations, that are made with the same equipments used for 150 liters refrigerators. Sharing between 150 and 300 liters refrigerators is present also in the secondary branches. In particular "tubes production" and "electronic devices" assembly line are completely shared, while only the last operation of the "door production" line is shared.

For what concerns the data reported inside the process boxes, both Cycle Time (CT) and Change Over Time (CO) are determined based on a weighted average of the three families of 150 liters refrigerators. This seemed to be a meaningful approach because across each families, there are just little differences in times. Furthermore Up Time (UT) denotes the percentage of time that a resource is available for production and it takes into account time lost for breakages, set up and, in the case of shared resource, the percentage of productive capacity dedicated to a product family.

The time line at the bottom represents manufacturing processing time and inventory time. The estimated LT is equal to 41 hours while the value added time is only 39 minutes, so there is a great margin of improvement.

\subsection{Criticalities analysis}

The next step was the definition of a new system, to pull orders through the line. Before doing this it was necessary to analyze the inefficiencies encountered on the process and evaluate if such problems were due to inefficiency spread among the whole critical 
value stream or due to inefficiencies concentrated in correspondence of the insertion points. As a results it was observed that the insertion points corresponding to the conjunction of the main value stream with the "tube assembly" lines and with the "electronic devices preassembly" line were not critical ones. Although both processes are shared (a typical cause of criticality) operations are manual with short cycle time and qualified worker are not requested. Thus it is easy to reallocate workers in case of necessity, so that the main value stream can always be feeded. In addition, the output of both these processes is a low cost generic WIP, so maintaining a buffer to separate processes is acceptable, for it does not increase costs and facilitates production control.

On the contrary, the insertion point corresponding to the conjunction of the main stream with the "door assembly" line was judged to be critical. In fact the "door assembly" station, that is the process bottle neck, was usually starving for shortage in doors replenishment. For that reason, the throughput was reduced and the LT increased.

Thus, an additional map was developed to analyze the causes of this inefficiency. The obtained CSM for the sub- critical value stream is shown in Figure 12.

Figure 12 Here

It was found that the problem was linked with the presence of sharing at the "seal insertion" machine. To minimize set up when production skipped from 150 liters to 300 liters refrigerators, orders were scheduled in large batch, increasing the probability of starving at the "door assembly station".

\subsection{Future State Mapping}

Following the proposed approach, the future state map was developed splitting the value stream into three consecutive parts, that were improved in the following order: 
1. the process upstream the critical insertion point;

2. the secondary but critical value stream (door assemble line);

3. the process downstream the critical insertion point.

Figure 13 shows the obtained future state map for the process.

Figure 13 Here

It can be noted that the "final assembly" station was chosen as the pacemaker process to pull orders through the line. Order are released from the production control and inserted in the backlog list at the pacemaker process. Then order are released backward in the line by aim of a kanban system.

Whenever possible production station have been re-organized into " $U$ shaped cell" in order to obtained a "one by one" production flow. Alternatively productions were connected using FIFO lines. In that way the process was divided into four "micro factories" synchronized through a kanban system.

To level the production mix at the pacemaker process, an EPE (every part every ) of 4 hours was established. So all three families will be manufactured twice a day. This was due to the fact that, even reducing change over time of $30-40 \%$, the maximum number of set up at the foaming machine is equal to eight, as shown in the following relation:

$$
N^{\circ} \text { SetUP }=\left\lfloor\frac{\text { Tot.AvailableTime-Tot.ThroughpufTime }}{\text { AverageSeUpTime }}\right\rfloor=\left\lfloor\frac{8 \cdot 60-(1 \cdot 300+15)}{20}\right\rfloor=8
$$

In particular choosing 6 set up per day gives an addition margin of security, to face potential problems or variation in the demand level.

As shown in Figure 13, a Signal Kanban corresponding to a batch of 150 items, is needed to link the "sheets cutting" machines with the assemble line. This was due to the 
fact that, even reducing change over time of $50 \%$, the maximum number of set up is equal to 4 , thus assuring the production of two families per day.

This is shown in the following relation:

$$
N^{\circ} \operatorname{Set} U P=\left\lfloor\frac{8 \cdot 60 \cdot 0.7-(25 \cdot 600) / 60}{20}\right\rfloor=4
$$

where:

- $70 \%$ is the productive capacity assured to the 150 liters refrigerators line;

- 600 is the number of items processed (300 refrigerator bodies +300 refrigerator doors).

Please note that this solution requires the presence of a buffer with an average WIP level equal to 225 items corresponding to 6 hours. This is acceptable, for the WIP at this stage is not expensive and it does not increase manufacturing costs but facilitates production control.

By aim of these improvements, the total productive LT has been reduced to 13 hours, corresponding to a $68 \%$ reduction in respect to the initial 41.5 hours.

\section{CONCLUSIONS}

The paper focused on VSM that has been indicated as one of the best tool for Lean Production implementation in a facility. This method is not easy to use in the case of complex production processes characterized by multiple flows that merge. To address this problem a new framework "Improved Value Stream Mapping" has been developed. This was done through an integration of the standard VSM approach with a set of additional tools derived from the manufacturing engineering area. In particular the framework is structured in order to explore the various branches of the whole value stream only if necessary and following an optimized order. 
To be proved, the framework was finally applied to a refrigerators production process. As a results it was demonstrated that IVSM has the following main advantages:

- it offers a structured way to choose the key elements of a complex production process and to perform an optimized analysis of the whole value stream;

- it is successful in handling multiple products having non identical routings;

- it is successful in handling complex BOM with multiple level as well as multiple flows that merge.

Future works are intended to integrate the approach with economic measures to express both value added and non value added costs sustained through the process. An additional field for future research can be that to evaluate also the variances of the analyzed manufacturing process, by aim of a statistical and/or fuzzy approach.

\section{REFERENCES}

Emiliani M., 2000, Cracking the code of business, Management Decision, 38, 60-79.

Hines P., Rich N., 1997, The seven value stream mapping tool, International Journal of Operations \& Production Management, 17, 46-64.

Hines P., Taylor D., 2000, Going Lean, Cardiff Lean Enterprise Research Center, Cardiff Business School.

Irani A, Khaswala N.,., 2000, Value Network Mapping (VNM): visualization and analysis of multiple flows in Value Stream Maps, www-iwse.eng.ohio-state.edu/ (Department of Industrial, Welding and System Engineering, The Ohio State University Columbus Ohio 43210). 
Lian Y., Van Landeghem H., 2002, An application of simulation and Value Stream Mapping in Lean Manufacturing, $14^{\text {th }}$ European Simulation Symposium, SCS Europe BVBA.

McDonald T., Van Aken E.M., Rentes A.F., 2002, Utilising Simulation to Enhance Value Stream Mapping: A Manufacturing Case Application, International Journal of Logistic: Research and Application, 5, 213-232.

Offodile O.F., Grznar J., Part family formation for variety reduction in flexible manufacturing systems, 1997, International Journal of Operations \& Production Management, 3, 291-304.

Tapping D., Luyster T., Shuker T., 2002 Value Stream Management, New York, Productivity Press

Rother M., Shook J., 1999, Learning to see: Value Stream Mapping to Add Value and Eliminate Muda, Brookline, MA, The Lean Enterprise Institute.

Selim H., Reda M.S., Mahdi A., 2003, Formation of machine groups and part families: a modified SLC method and comparative study, Integrated Manufacturing Systems, 14, $123-137$

Veramani D., Mani K., 1996, 'Optimal clustering in vertex-tree graphic matrices, International Journal of Production Research, 34, 2587-2611.

Womak J.P., Jones D., 1996, Lean Thinking: Banish Waste and Create Wealth in Your Corporation, New York: Simon \& Schuster.

Zhou J., Irani S.A., 2003, A New Flow Diagramming Scheme For Mapping And Analysis Of Multi-Product Flows In A Facility, Process Journal of Integrated Design and Process Science, 7, 26-58. 


\section{Future State Questions}

1) What is the takt time?

2) Will production produce to finished goods supermarket or directly to shipping?

Basic 3) Where can continuous flow processing be utilized?

4) Is there a need for a supermarket pull system within the value stream (kanban - conwip) ?

5) What single point in the production chain will be used to schedule production ?

Heijunka

6) How will the production be leveled at the pacemaker process ?

7) What increment of work will be consistently released from the pacemaker process(pitch) ?

Kaizen $\quad$ 8) What process improvements will be needed?

Table 1: Design Question for Future State Map 


\begin{tabular}{|l|c|c|c|c|c|c|c|c|c|c|c|c|c|c|c|}
\hline & M\#1 & M\#2 & M\#3 & M\#4 & M\#5 & M\#6 & M\#7 & M\#8 & M\#9 & M\#10 & M\#11 & M\#12 & M\#13 & M\#14 & M\#15 \\
\hline P\#1 & & & & & 1 & 1 & 1 & & & 1 & & 1 & 1 & & \\
\hline P\#2 & 1 & & 1 & & & & 1 & & 1 & & & & & 1 & 1 \\
\hline P\#3 & & 1 & & 1 & & & & & & & 1 & 1 & & & \\
\hline P\#4 & & & & & 1 & 1 & & 1 & & 1 & & 1 & & & \\
\hline P\#5 & 1 & & 1 & & & & 1 & 1 & 1 & & & & & 1 & 1 \\
\hline P\#6 & 1 & & & 1 & & & 1 & & 1 & & & & & 1 & 1 \\
\hline P\#7 & & & & & 1 & 1 & & 1 & & 1 & & 1 & 1 & & \\
\hline P\#8 & & 1 & & 1 & & & & & & & 1 & & 1 & & \\
\hline P\#9 & & & & & 1 & 1 & 1 & & & 1 & & & 1 & & \\
\hline P\#10 & & 1 & & 1 & & & & & & & 1 & & 1 & & 1 \\
\hline
\end{tabular}

Table 2: Machine Part Matrix 


\begin{tabular}{|c|c|c|c|c|c|c|c|c|c|c|}
\hline & P\#1 & P\#2 & P\#3 & P\#4 & P\#5 & P\#6 & P\#7 & P\#8 & P\#9 & P\#10 \\
\hline P\#1 & 1 & 0,231 & 0,301 & 0,763 & 0,199 & 0,231 & 0,85 & 0,301 & 0,921 & 0,264 \\
\hline P\#2 & & 1 & 0 & 0 & 0,928 & 0,85 & 0 & 0 & 0,264 & 0,264 \\
\hline P\#3 & & & 1 & 0,342 & 0 & 0,301 & 0,301 & 0,809 & 0 & 0,732 \\
\hline P\#4 & & & & 1 & 0,231 & 0 & 0,921 & 0 & 0,672 & 0 \\
\hline P\#5 & & & & 1 & 0,784 & 0,199 & 0 & 0,231 & 0,231 \\
\hline P\#6 & & & & & 1 & 0 & 0,301 & 0,264 & 0,438 \\
\hline P\#7 & & & & & & & 1 & 0,301 & 0,763 & 0,264 \\
\hline P\#8 & & & & & & & 1 & 0,342 & 0,912 \\
\hline P\#9 & & & & & & & & & 1 & 0,301 \\
\hline P\#10 & & & & & & & & & & 1 \\
\hline
\end{tabular}

Table 3: Similarity Matrix 


\begin{tabular}{|c|c|c|c|c|c|c|c|c|c|c|c|}
\hline & \multicolumn{3}{|c|}{ Family \#1 } & \multicolumn{4}{|c|}{ Family \#2 } & \multicolumn{3}{|c|}{ Family \#3 } \\
\hline & & P\#5 & P\#2 & P\#6 & P\#4 & P\#7 & P\#1 & P\#9 & P\#8 & P\#10 & P\#3 \\
\hline \multirow{6}{*}{$\frac{\overline{\#}}{\overline{\bar{\Phi}}}$} & M\#1 & 1 & 1 & $\overline{1}$ & & & & & & & \\
\hline & M\#14 & 1 & 1 & 1 & & & & & & & \\
\hline & M\#9 & 1 & 1 & 1 & & & & & & & \\
\hline & M\#7 & 1 & 1 & 1 & & & 1 & 1 & & & \\
\hline & M\#15 & 1 & 1 & 1 & & & & & & 1 & 1 \\
\hline & M\#3 & 1 & 1 & & & & & & & & \\
\hline \multirow{5}{*}{$\frac{\mathbb{\#}}{\overline{\overline{0}}}$} & M\#5 & & & & 1 & 1 & 1 & 1 & & & \\
\hline & M\#6 & & & & 1 & 1 & 1 & 1 & & & \\
\hline & M\#10 & & & & 1 & 1 & 1 & 1 & & & \\
\hline & M\#12 & & & & 1 & 1 & 1 & & 1 & & \\
\hline & M\#8 & 1 & & & 1 & 1 & & & & & \\
\hline \multirow{4}{*}{ 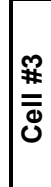 } & M\#13 & & & & 1 & & & 1 & & 1 & 1 \\
\hline & M\#4 & & & 1 & & & & & 1 & 1 & 1 \\
\hline & M\#2 & & 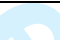 & & & & & & 1 & 1 & 1 \\
\hline & M\#11 & & 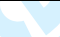 & & & & & & 1 & 1 & 1 \\
\hline
\end{tabular}

Table 4: Rearranged Machine Part Matrix 


\section{Figures Captions}

Figure 1: Actual State Map Icons

Figure 2: Future State Map Icons

Figure 3: Improved Value Stream Mapping Procedure

Figure 4: PQ\$ Analysis Chart

Figure 5: Part Families Dendrogram

Figure 6: Possible Solution to Synchronize Flow

Figure 7: Example of Internal Machine Sharing

Figure 8: Example of TBOM

Figure 9: Refrigerators Production Process

Figure 10: Refrigerator Simplified TBOM

Figure 11: Critical Path CSM

Figure 12: Sub - Critical Path CSM

Figure 13: Refrigerators FSM 


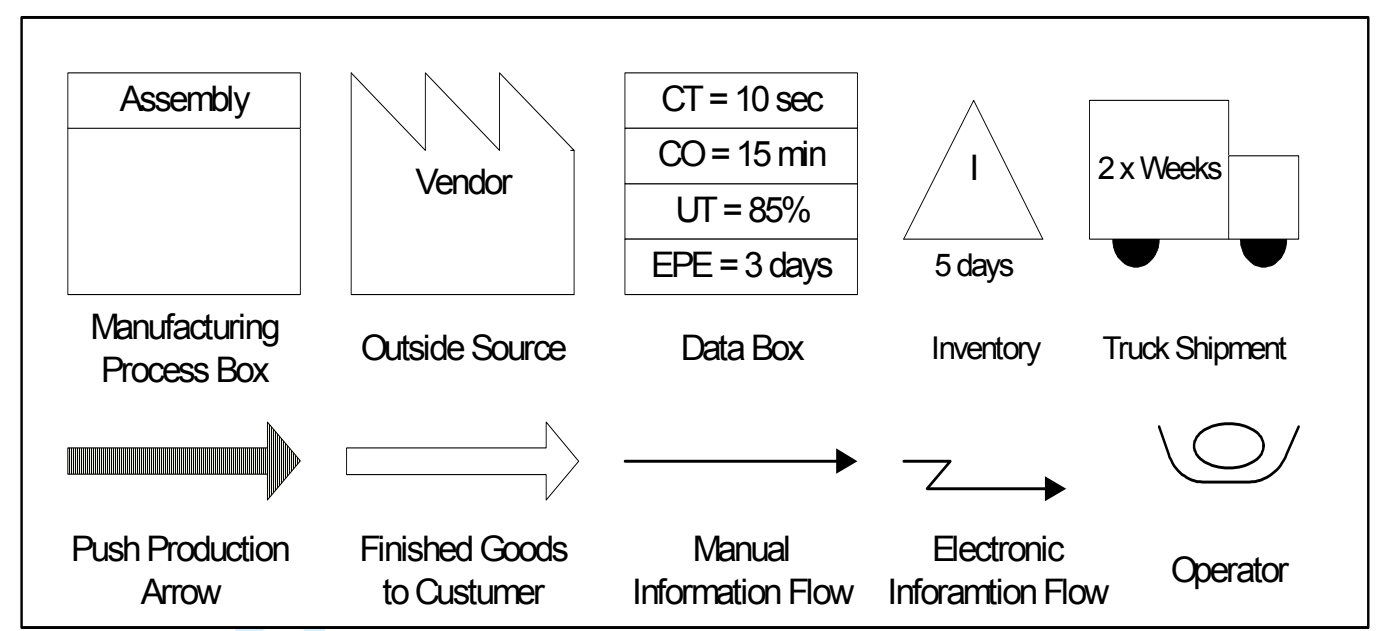

Figure 1: Actual State Map Icons 


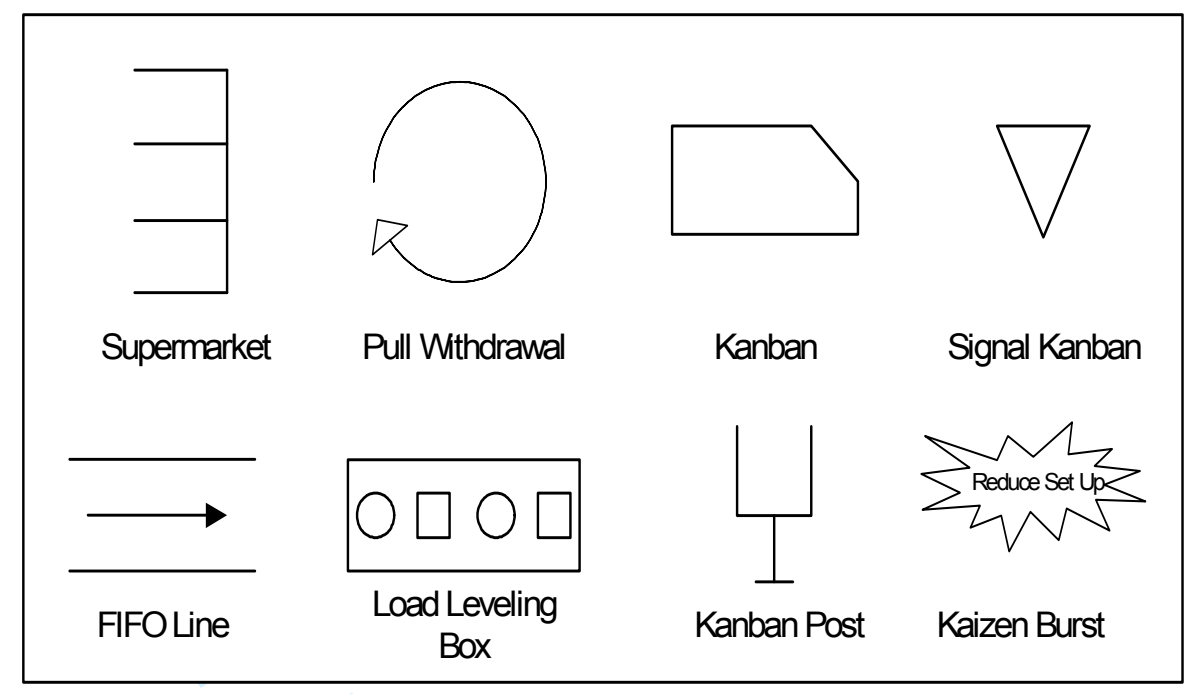

Figure 2: Future State Map Icons 
1

2

3

4

5

6

7

8

9

10

11

12

13

14

15

16

17

18

19

20

21

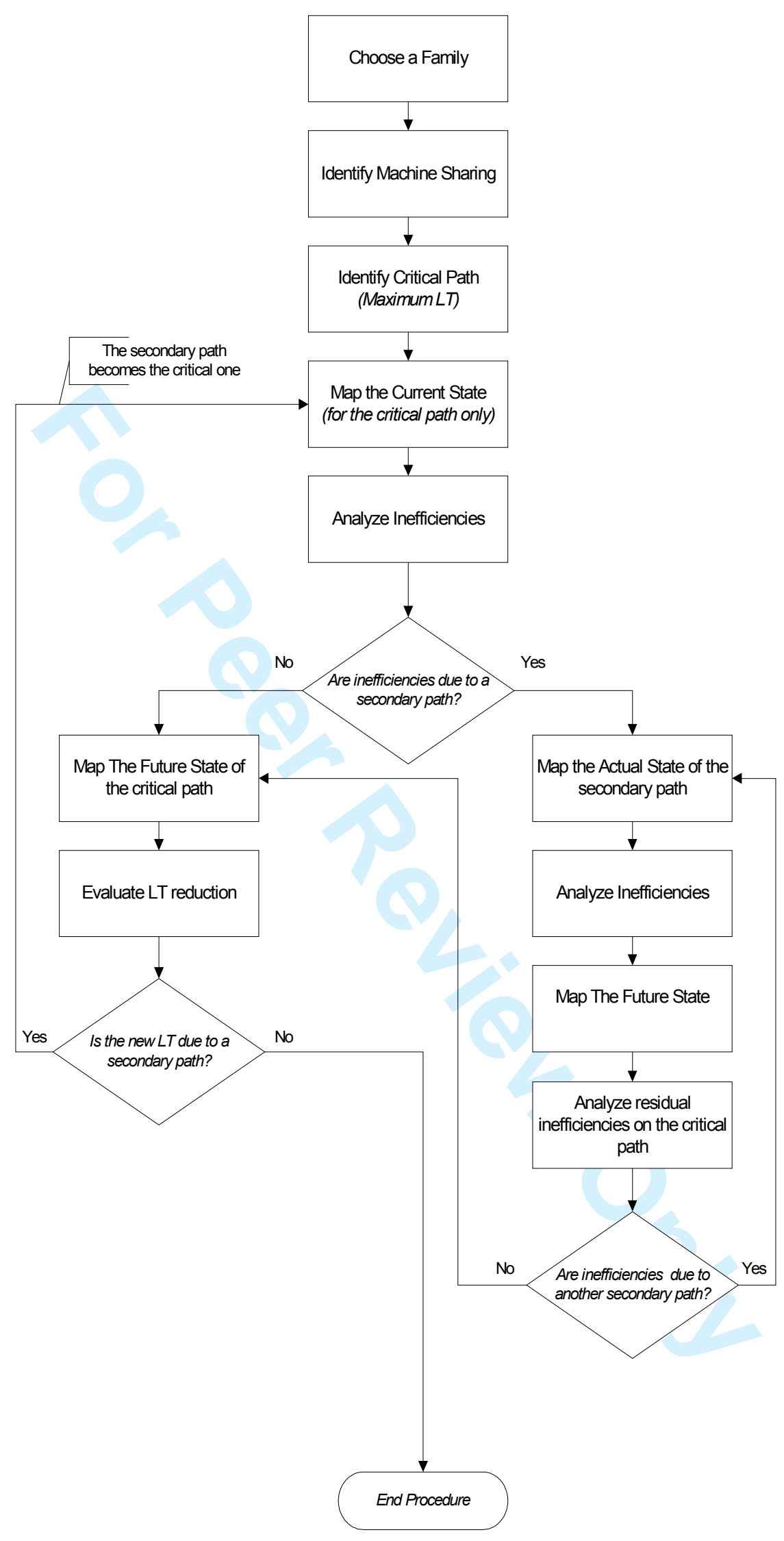

Figure 3: Improved Value Stream Mapping Procedure 

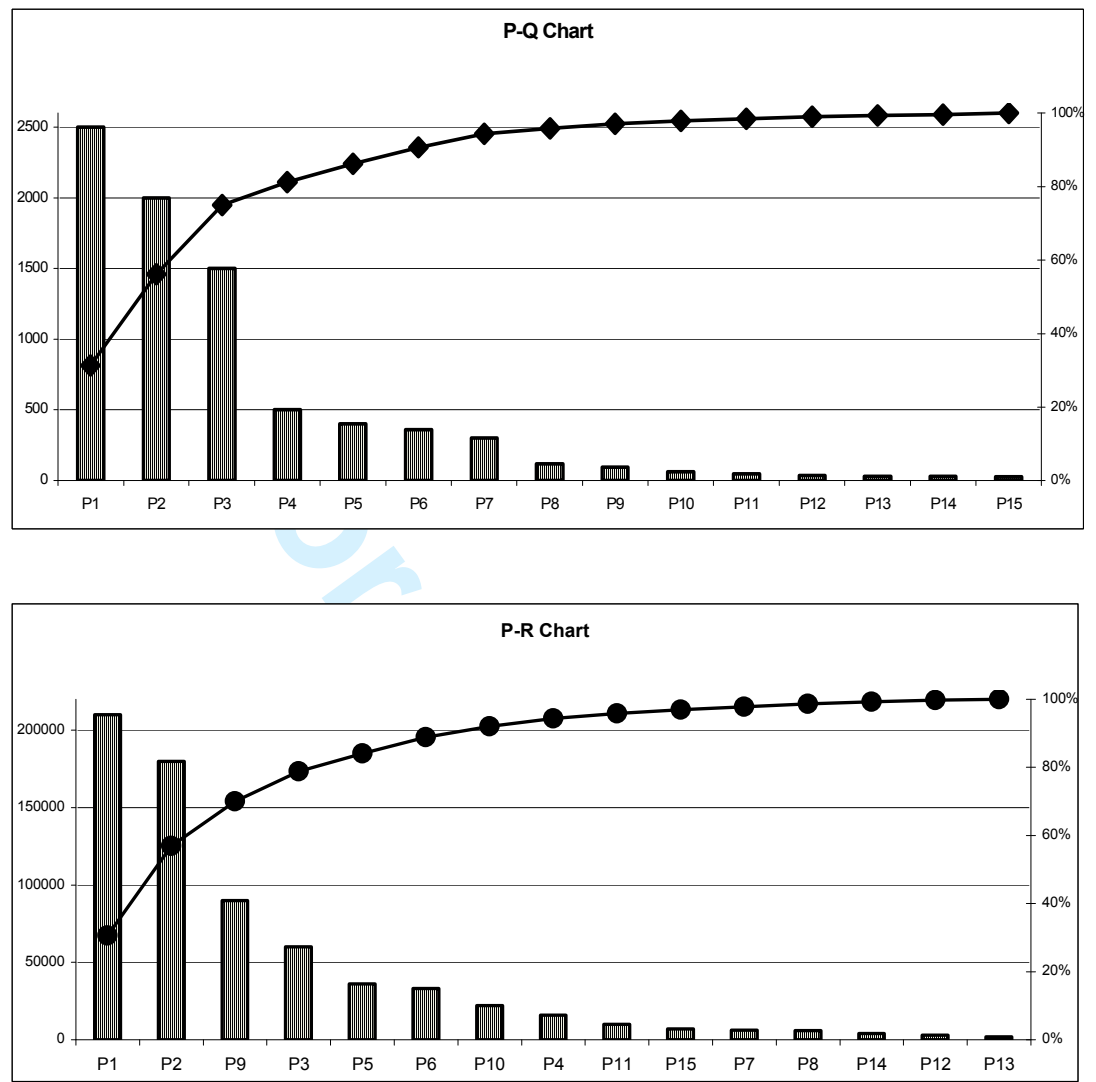

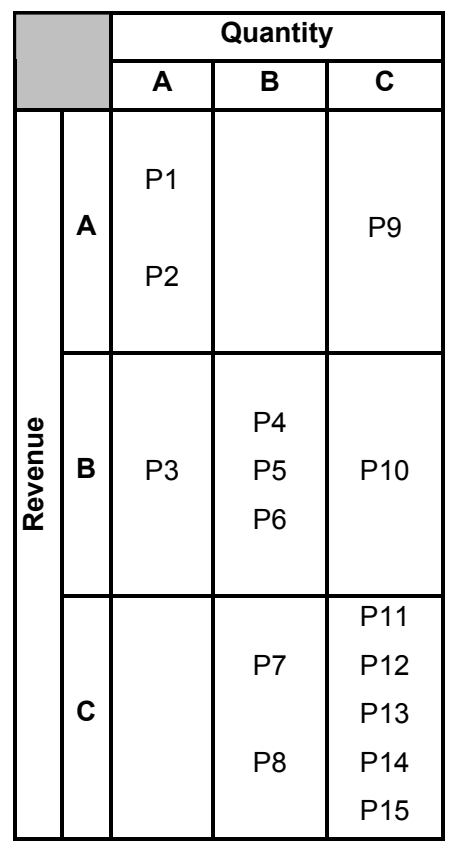

Figure 4: PQ\$ Analysis Chart 


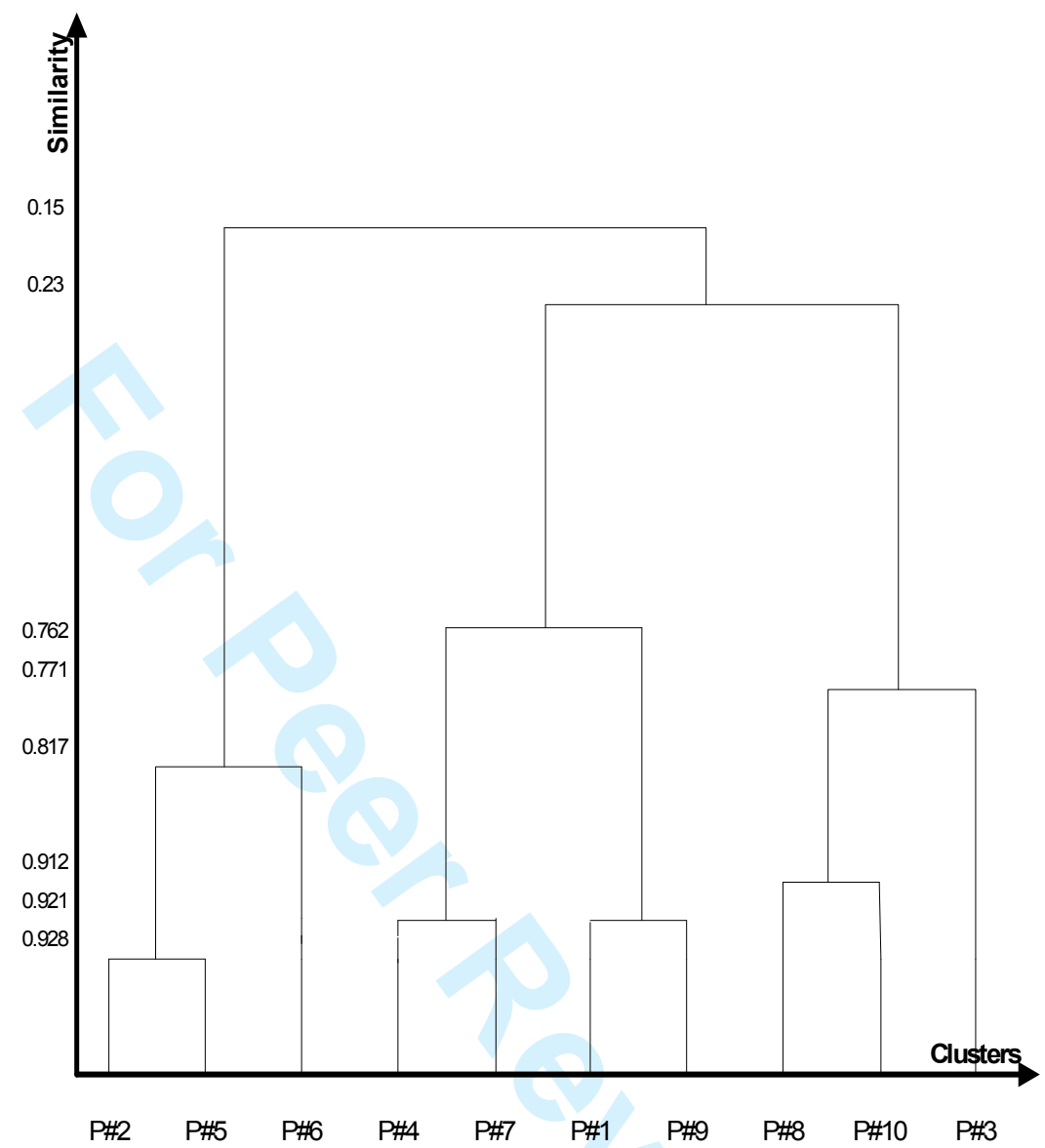

Figure 5: Part Families Dendrogram 


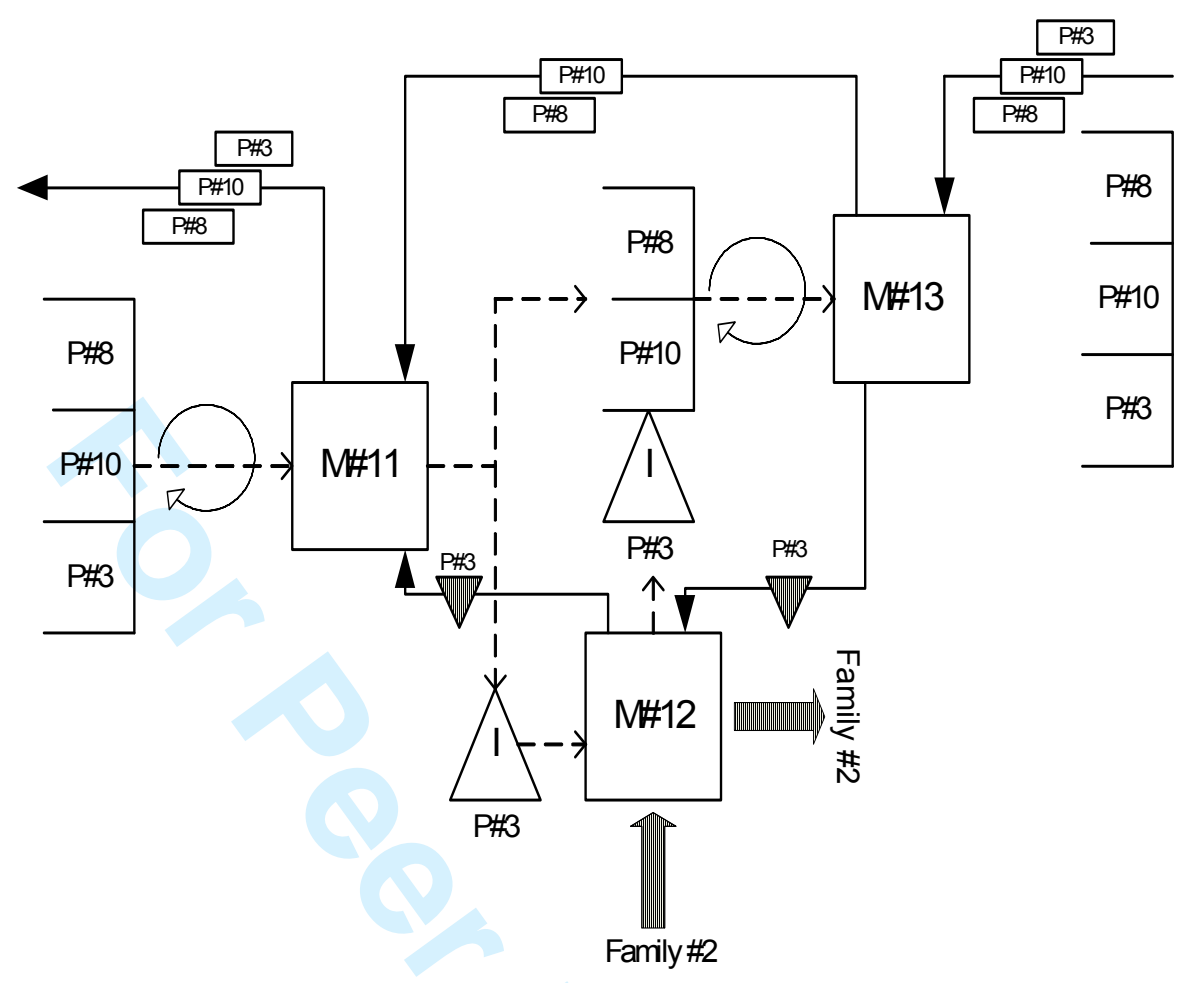

Figure 6: Possible Solution to Synchronize Flow 


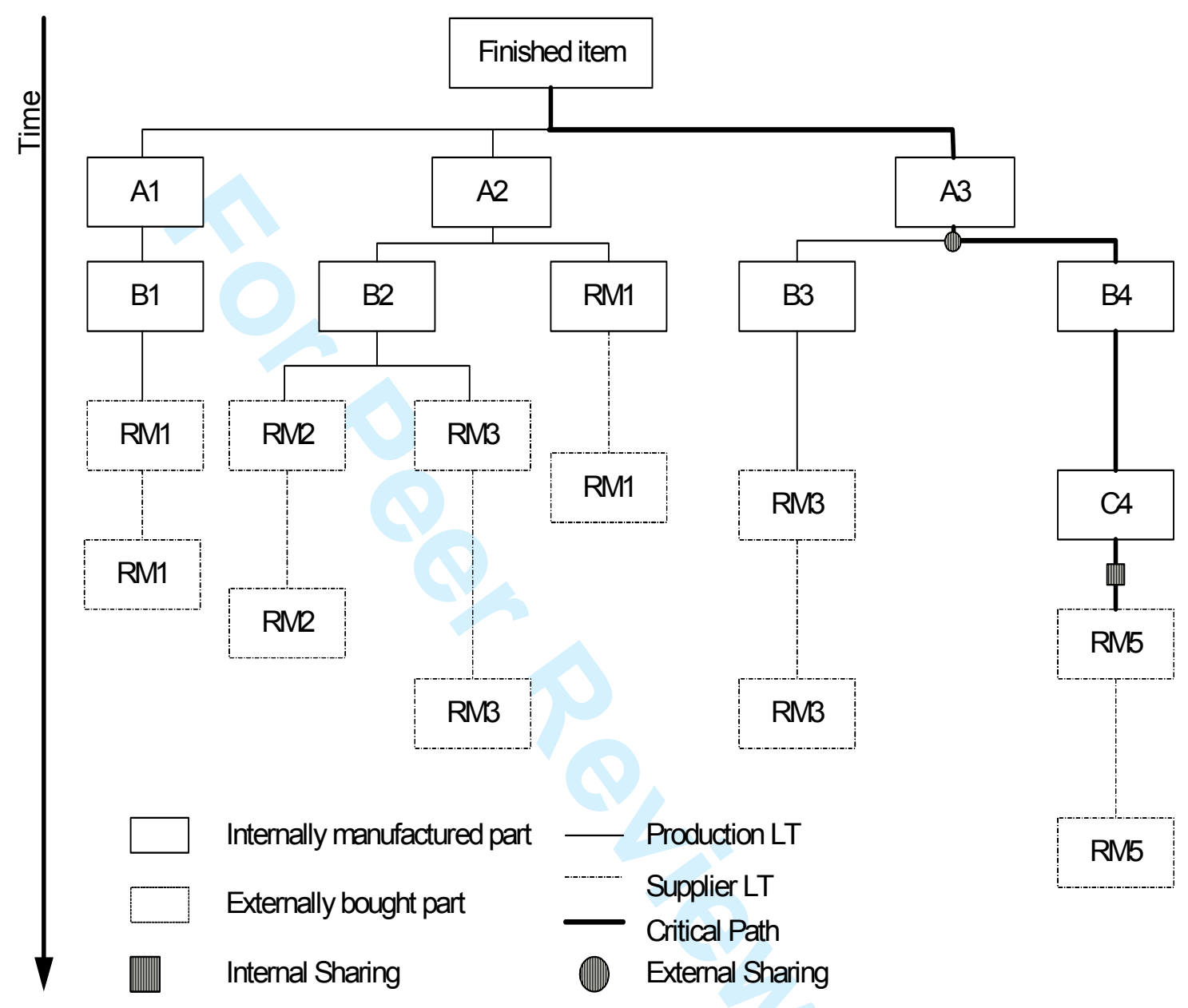

Figure 8: Example of TBOM 


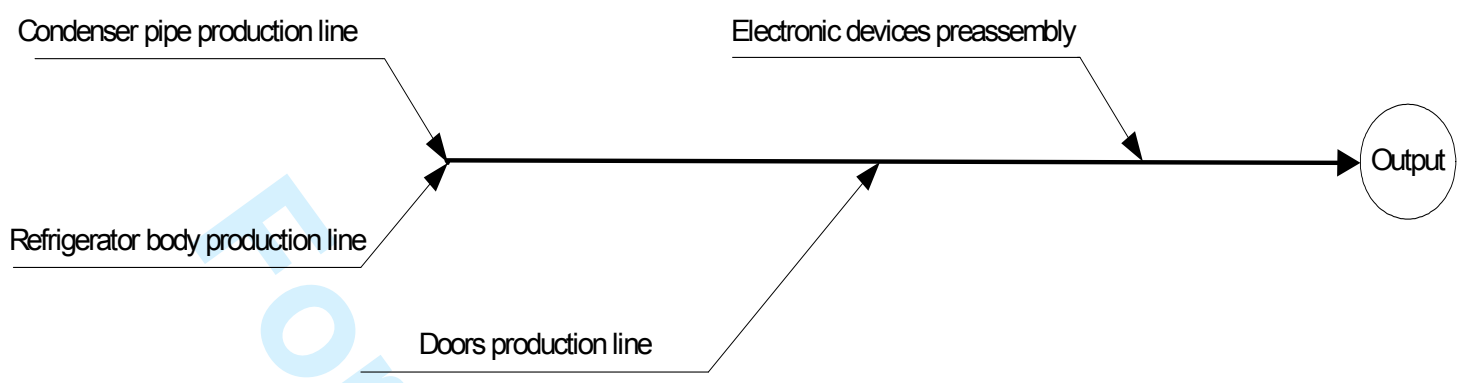

Figure 9: Refrigerators Production Process 


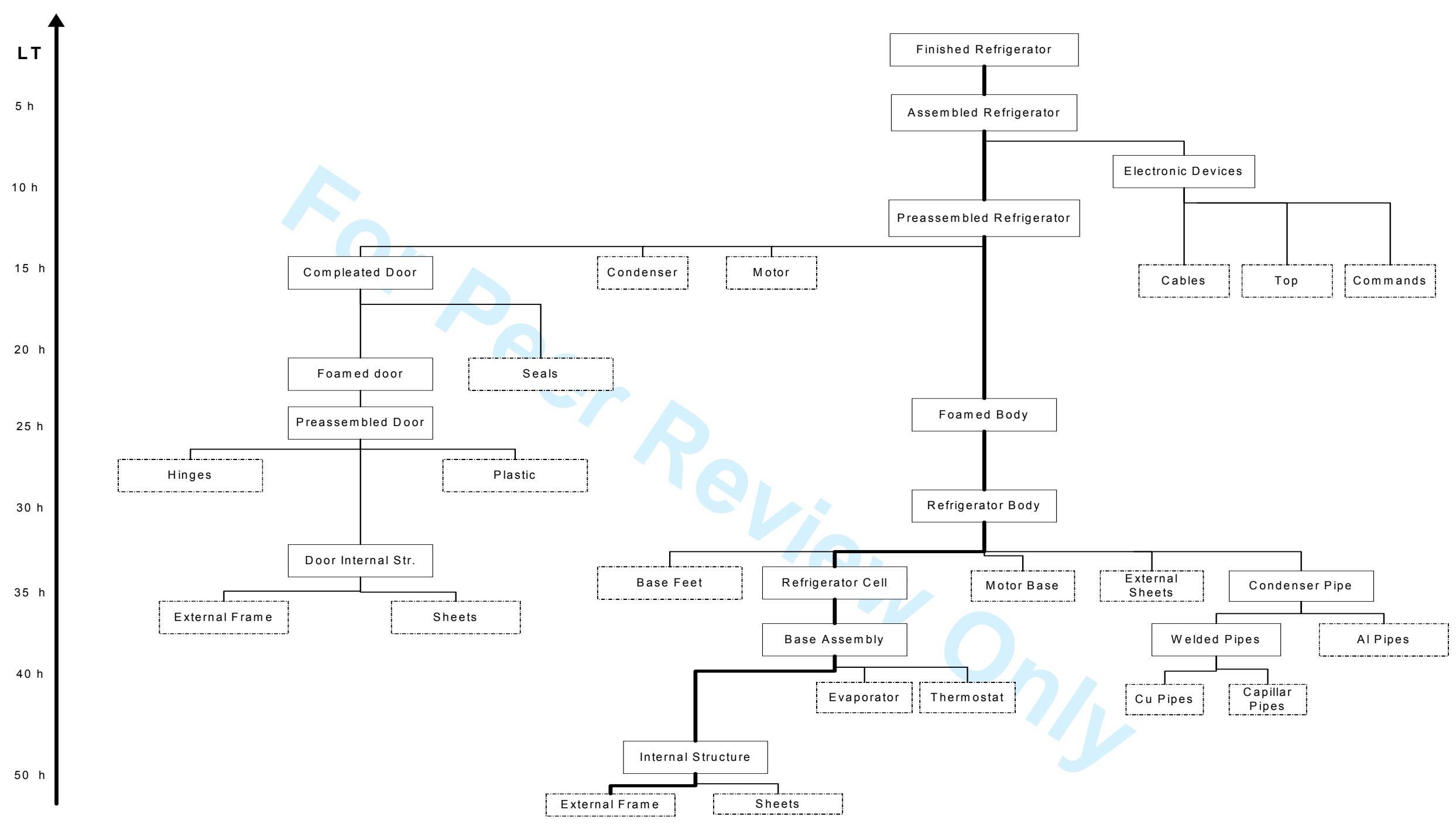

Figure 10: Refrigerator Simplified TBOM 


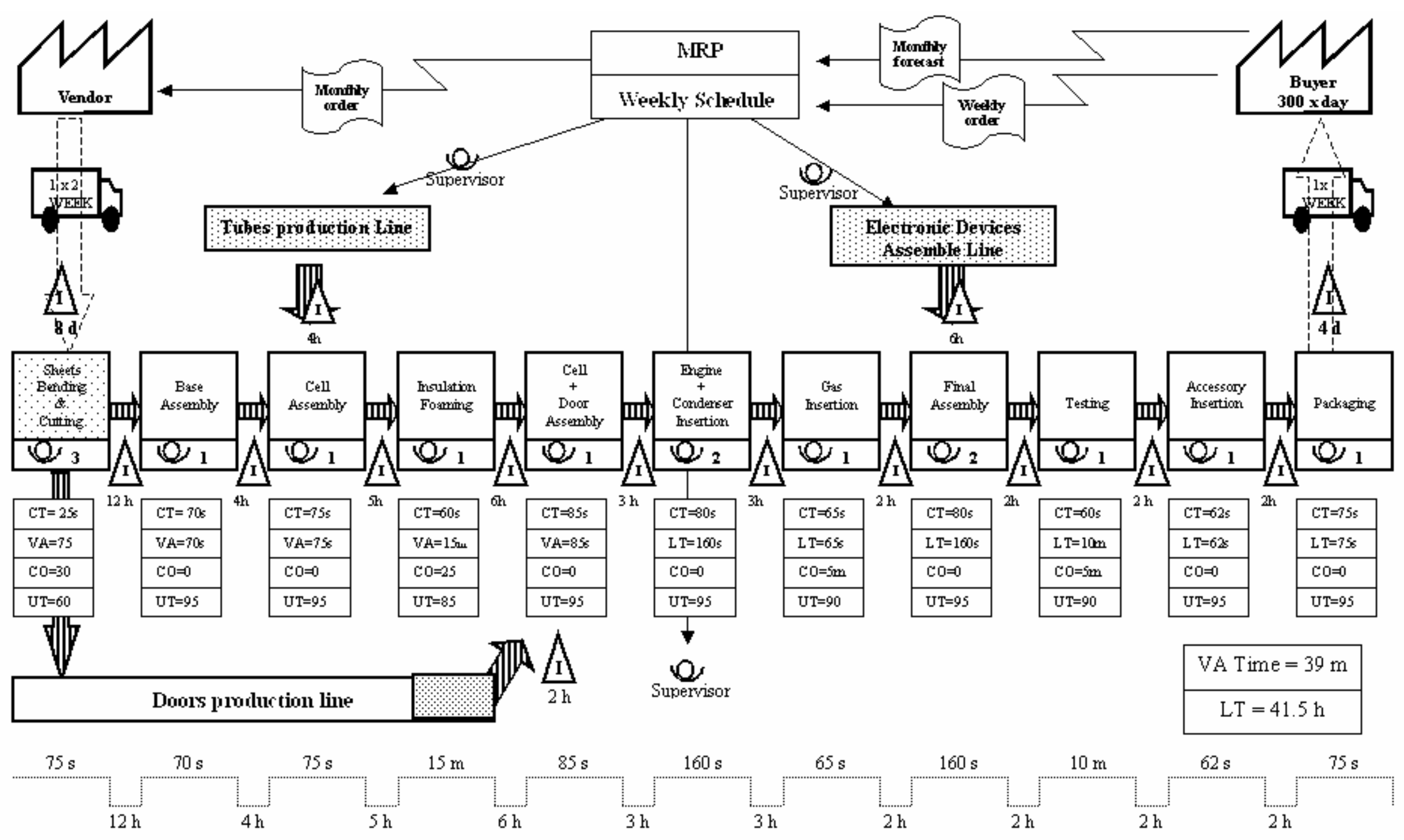

Figure 11: Critical Path CSM 


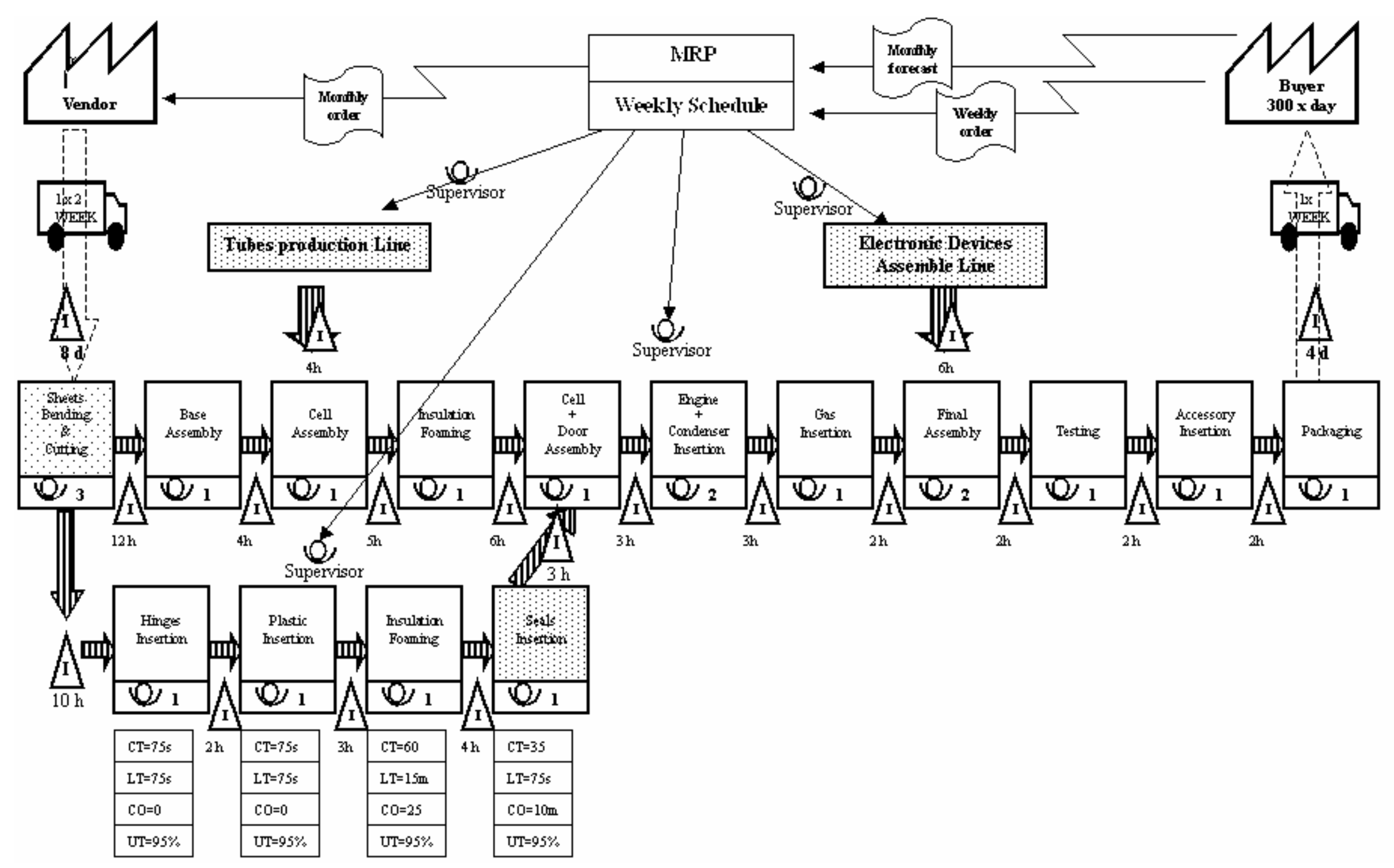

Figure 12: Sub - Critical Path CSM 


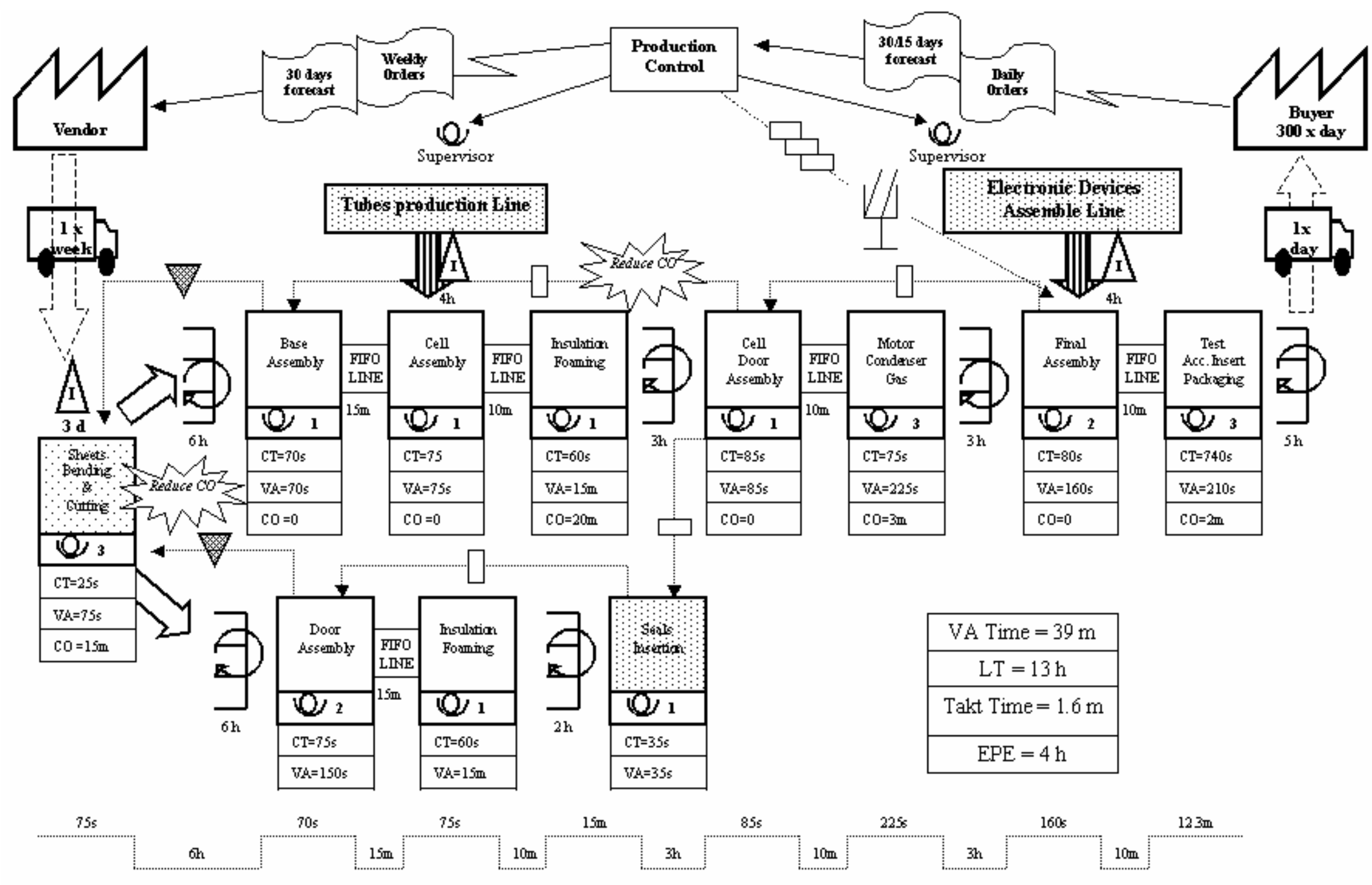

Figure 13: Refrigerators FSM 